\title{
Kinetics of rapamycin production by Streptomyces hygroscopicus MTCC 4003
}

\author{
Subhasish Dutta $\cdot$ Bikram Basak $\cdot$ Biswanath Bhunia $\cdot$ \\ Samayita Chakraborty $\cdot$ Apurba Dey
}

Received: 10 September 2013 / Accepted: 20 November 2013/Published online: 1 December 2013

(C) The Author(s) 2013. This article is published with open access at Springerlink.com

\begin{abstract}
Research work was carried out to describe the kinetics of cell growth, substrate consumption and product formation in batch fermentation of rapamycin using shake flask as well as laboratory-scale fermentor. Fructose was used as the sole carbon source in the fermentation media. Optimization of fermentation parameters and reliable mathematical models were used for the maximum production of rapamycin from Streptomyces hygroscopicus MTCC 4003. The experimental data for microbial production of rapamycin fitted well with the proposed mathematical models. Kinetic parameters were evaluated using best fit unstructured models, viz. Andrew's model, Monod model, Yano model, Aiba model. Andrew's model showed a comparatively better $R^{2}$ value $(0.9849)$ among all tested models. The values of maximum specific growth rate $\left(\mu_{\max }\right)$, saturation constant $\left(K_{\mathrm{S}}\right)$, inhibition constant $\left(K_{\mathrm{i}}\right)$, and growth yield coefficient $\left(Y_{\mathrm{X} / \mathrm{S}}\right)$ were found to be 0.008 $\left(\mathrm{h}^{-1}\right), 2.835(\mathrm{~g} / \mathrm{L}), 0.0738(\mathrm{~g} / \mathrm{L})$, and $0.1708\left(\mathrm{~g} \mathrm{~g}^{-1}\right)$, respectively. The optimum production of rapamycin was obtained at $300 \mathrm{rpm}$ agitation and $1 \mathrm{vvm}$ aeration rate in the fermentor. The final production of rapamycin in shake flask was $539 \mathrm{mg} / \mathrm{L}$. Rapamycin titer found in bioreactor was $1,316 \mathrm{mg} / \mathrm{L}$ which is $52 \%$ higher than the latest maximum value reported in the literature.
\end{abstract}

Keywords Rapamycin - Growth kinetics - Streptomyces hygroscopicus · Antibiotic · Substrate inhibition

S. Dutta $\cdot$ B. Basak $\cdot$ S. Chakraborty $\cdot$ A. Dey $(\bowtie)$ Department of Biotechnology, National Institute of Technology Durgapur, Mahatma Gandhi Avenue, Durgapur 713209, India e-mail: apurbadey.bt@gmail.com; apurba.dey@bt.nitdgp.ac.in

B. Bhunia

Department of Bio Engineering, National Institute of Technology Agartala, Barjala, Tripura 799055, India

\author{
Abbreviations \\ $\mathrm{d} P / \mathrm{d} t \quad$ Production rate $\left(\mathrm{mg} / \mathrm{L} \mathrm{h}^{-1}\right)$ \\ $K_{\mathrm{S}} \quad$ Saturation coefficient $(\mathrm{g} / \mathrm{L})$ \\ $K_{\mathrm{i}} \quad$ Inhibition coefficient $(\mathrm{g} / \mathrm{L})$ \\ $m \quad$ Cell maintenance coefficient \\ $P_{0}, P$ Product concentration at 0 th $\mathrm{h}$ of fermentation \\ $(\mathrm{mg} / \mathrm{L})$, product concentration at particular time of \\ fermentation $(\mathrm{mg} / \mathrm{L})$ \\ $R^{2} \quad$ Regression coefficient \\ $R_{\mathrm{t}} \quad$ HPLC retention time (min) \\ $S_{0}, S \quad$ Initial substrate concentration $(\mathrm{g} / \mathrm{L})$, limited \\ substrate concentration $(\mathrm{g} / \mathrm{L})$ \\ $t \quad$ Incubation time (h) \\ vvm Volume of air per volume of fermentation media \\ per minute $\left(\mathrm{m}^{3}\right)$ \\ $X_{0}, X$ Initial cell mass concentration $(\mathrm{g} / \mathrm{L})$, cell mass \\ concentration at any time of fermentation $(\mathrm{g} / \mathrm{L})$ \\ $Y_{\mathrm{X} / \mathrm{S}} \quad$ Growth yield coefficient per unit substrate \\ consumed $\left(\mathrm{g} \mathrm{g}^{-1}\right)$
}

\section{Greek symbols}

$\mu, \mu_{\max }$ Specific growth rate $\left(\mathrm{h}^{-1}\right)$, maximum specific growth rate $\left(\mathrm{h}^{-1}\right)$

\section{Introduction}

Rapamycin, also known as sirolimus, is an antibiotic commonly used as a potent antifungal and immunosuppressant drug produced by the soilborne actinomycete Streptomyces hygroscopicus (Fang and Demain 1995). It has also been reported to have antitumor, neuroprotective and anti-aging properties (Zou and Li 2013). In recent time, because of its exceptional biological and pharmaceutical potential it has generated interest for its therapeutic use

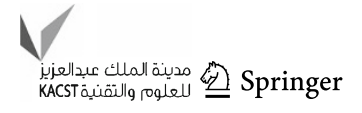


(Graziani 2009; Sehgal 2003). Its immunosuppressive activity due to inhibition of T-cell activation and proliferation has led to its potential use in clinical treatment of graft rejection in organ transplant (Weber et al. 2005) and autoimmune diseases such as rheumatoid arthritis (Foroncewicz et al. 2005). In addition to its therapeutic usefulness, semisynthetic derivatives of rapamycin has also been shown to display activities against cancer (Park et al. 2010), Parkinson's disease (Tain et al. 2009), and AIDS (Nicoletti et al. 2009). Its anti-aging activity has been published recently when scientists observed its ability to extend the life span of mice (Zou and Li 2013).

The mechanism of action of rapamycin is distinct from that of cyclosporine A and FK-506. The latter drugs inhibit the first phase of T-cell activation by blocking calcineurin, serine/threonine phosphatase (transcriptional activator of IL-2 gene); whereas, rapamycin interferes with the second phase of T-cell activation by blocking the IL-2 dependent signal transduction (Morelon et al. 2001). The anti-proliferative effects of rapamycin are mediated through the formation of an active complex with a cytosolic protein FK-506 and binding protein (FKBP12) allowing this drug receptor complex to interact with a putative lipid kinase (Wiederrecht et al. 1995), and inhibits the $289 \mathrm{kDa}$ RAFT/ FRAP proteins called mTOR (mammalian target of rapamycin) (Sabatini et al. 1995).

Despite the versatile activities and resultant demand of this drug, its use may be trimmed because of the low titer of rapamycin produced by $S$. hygroscopicus. The low titer of this drug produced by the organism has now become a rate-limiting factor in further development and industrialization of this natural product (Zhu et al. 2010). In the past decades, most efforts have focussed on rapamycin biosynthesis (Park et al. 2010; Graziani 2009), its pharmaceutical activities (Prapagdee et al. 2008; Park et al. 2010; Weber et al. 2005; Foroncewicz et al. 2005; Nicoletti et al. 2009), strain improvement (Zhu et al. 2010; Xu et al. 2005; Chen et al. 2009) and optimization of physiological factors for better production of rapamycin (Zou and Li 2013; Chen et al. 2008). In the literature, although there are many reports describing optimization of the media (Refaat and Abdel-Fatah 2008) and improvement of strain for better production of rapamycin (Xu et al. 2005; Jung et al. 2011), kinetic studies of growth and rapamycin production by S. hygroscopicus have not been satisfactorily done yet. Though an attempt was made by Schuhmann and Bergter investigating the branch formation, and cytological properties of mycelial growth of Streptomyces hygroscopicus on solid media (Schuhmann and Bergter 1976), the actual growth and rapamycin production kinetic parameters were not determined.

The metabolism and product formation pattern of a microorganism depend mainly on their fermentative, nutritional, physiological, and genetic nature (Prakasham et al. 2007; Bhunia et al. 2012). Exploitation of such microbial metabolism for the desired product formation by regulating the critical fermentation parameters helps in commercialization (Subba Rao et al. 2008). Hence, careful kinetic studies are required to monitor the growth of microorganisms and product formation pattern in presence of various substrates. Kinetic studies provide good quantitative information regarding the behavior of a system, which is essential for study of growth of the organism and consequent product formation (Bhunia et al. 2012).

In the present study, we used various unstructured kinetic models to characterize the growth and rapamycin production by $S$. hygroscopicus. The kinetic parameters obtained by fitting the experimental data of growth and product formation with the unstructured models can be effectively used to explain the relationship between microbial growth and substrate utilization.

\section{Materials and methods}

\section{Chemicals}

All chemicals used were of analytical and HPLC grade and purchased from Sigma Aldrich (USA), Himedia (India), and Merck (India). HPLC-grade rapamycin standard was purchased from Merck, Germany. Deionized water used for HPLC analysis was prepared by Ultrapure Water System (Arium $^{\circledR}, 611 \mathrm{UF}$, Sartorius, Germany).

\section{Microorganisms}

Streptomyces hygroscopicus MTCC 4003 and Candida albicans MTCC 227 (test organism) were procured in lyophilized form from microbial type culture collection (MTCC) Chandigarh, India. S. hygroscopicus was grown and maintained in a medium consisting of (in $\mathrm{g} / \mathrm{L}$ ), glucose 4 ; yeast extract 4 ; malt extract $10 ; \mathrm{CaCO}_{3} 2$. The $\mathrm{pH}$ of the medium was maintained at 7.2. C. albicans was grown on MYGP medium having the following composition $(\mathrm{g} / \mathrm{L})$ : malt extract 3; yeast extract 3; peptone 5; glucose $10(\mathrm{pH} 7)$.

Preparation of inoculum

Inoculum (seed culture) was prepared by inoculating thawed S. hygroscopicus spores into 250-mL Erlenmeyer flask containing $100 \mathrm{~mL}$ growth medium with the help of a sterile inoculating loop under aseptic condition. The flasks were then incubated at $25^{\circ} \mathrm{C}$ and $120 \mathrm{rpm}$ for 7 days. $S$. hygroscopicus and $C$. albicans were maintained by bimonthly transfer to fresh medium and stored at $4{ }^{\circ} \mathrm{C}$ after incubation at $25^{\circ} \mathrm{C}$ for 5 days. 
Fermentation in shake flask

Two percent $(\mathrm{v} / \mathrm{v})$ seed culture was transferred into the production media (previously optimized in our lab) having the following composition $(\mathrm{g} / \mathrm{L})$ : fructose 22 ; mannose 5 ; malt extract 10; casein 0.3; $\left(\mathrm{NH}_{4}\right)_{2} \mathrm{SO}_{4} 5.3 ; \mathrm{NaCl} 5$; $\mathrm{K}_{2} \mathrm{HPO}_{4} 4 ; \mathrm{ZnSO}_{4} \cdot 7 \mathrm{H}_{2} \mathrm{O} \quad 0.06 ; \mathrm{MgSO}_{4} \cdot 7 \mathrm{H}_{2} \mathrm{O} \quad 0.0025$; $\mathrm{MnSO}_{4} \cdot \mathrm{H}_{2} \mathrm{O} 0.012 ; \mathrm{FeSO}_{4} \cdot 7 \mathrm{H}_{2} \mathrm{O} 0.1 ; \mathrm{CoCl}_{2} \cdot 6 \mathrm{H}_{2} \mathrm{O} 0.010$; $\mathrm{Na}_{2} \mathrm{SO}_{4}$ 0.3; $\mathrm{CaCO}_{3} 3$ (pH 7.2). In another experiment, seed culture was inoculated into the same production media devoid of mannose where the amount of mannose was supplemented by fructose, as both have same empirical formula and molecular mass. Similarly, another two sets of production media were used which incorporated same amount of glucose, replacing fructose and mannose. Fructose, glucose and mannose were autoclaved separately and added to the production media aseptically so as to achieve the desired concentration in the media. Fermentation was carried out in 250-mL Erlenmeyer flasks, each contained $50 \mathrm{~mL}$ production medium and was incubated at $25{ }^{\circ} \mathrm{C}$ and $120 \mathrm{rpm}$ for 7 days. All the experiments were performed in triplicate.

Fermentation in stirred tank reactor (STR)

Further work was done in the 2.2-L stirred tank reactor (STR) with 2-L working volume and Biocommand Plus fermentation supervising software (New Brunswick Scientific Co. Inc. USA) for advanced online control which result in higher cell density and rapamycin productivity. The reactor vessel containing production medium was sterilized by autoclaving along with the silicon tubes of $0.5 \mathrm{~cm}$ diameter and reagent bottles containing $\mathrm{NaOH}$, $\mathrm{HCl}$, antifoam agent (silicon oil) and one empty reagent bottle used for transferring the inoculum at $15 \mathrm{psi}$ and $121.5^{\circ} \mathrm{C}$ for $15 \mathrm{~min}$. The $\mathrm{pH}$ probe was calibrated before autoclaving the reactor and set to 7.24 while the dissolved oxygen (DO) probe was calibrated after autoclaving and set to $100 \%$. pH was maintained at the set point 7.24 by supplying $0.1(\mathrm{~N}) \mathrm{NaOH}$ and $0.1(\mathrm{~N}) \mathrm{HCl}$ automatically to the fermentor with the help of peristaltic pumps. DO level was controlled by agitator speed and aeration rate during fermentation. Agitation was set at $300 \mathrm{rpm}$ with six-bladed turbine impellers. Compressed sterile air was sparged at 1 vvm cultivating for 7 days at $25{ }^{\circ} \mathrm{C}$.

Analytical procedures

During fermentation in shake flasks, the microbial growth under the submerged conditions appeared as spherical pellets. Hence, after inoculation, $50 \mathrm{~mL}$ of samples were taken from shake flask in $50 \mathrm{~mL}$ centrifuge tube at every $24 \mathrm{~h}$ interval starting from 0 th $\mathrm{h}$ and centrifuged at
3,500 rpm for $15 \mathrm{~min}$ (Cheng 1995). The sample from STR was collected in every $24 \mathrm{~h}$ interval in a $50-\mathrm{mL}$ centrifuge tube and centrifuged. After centrifugation, the supernatant obtained was taken in separate centrifuge tube and the cell pellet was washed twice with $3 \mathrm{~mL}$ of methanol by centrifuging at $200 \mathrm{rpm}$ for $15 \mathrm{~min}$. The methanolic extract was mixed with the supernatant and used for rapamycin concentration (Sallam et al. 2010). The cell pellets were dried at $80{ }^{\circ} \mathrm{C}$ to a constant weight for $48 \mathrm{~h}$ in a hot air oven. The biomass was expressed as dry weight in $\mathrm{g} / \mathrm{L}$.

Residual fructose concentration was determined by 3,5dinitrosalicylic acid (DNS) method (Miller 1959). A standard calibration curve of optical density versus known concentration of fructose was prepared and the unknown concentration of residual fructose in the media was determined from this curve.

Bioassay determination of rapamycin was performed by "paper-disc agar diffusion method" as described by Kojima et al. (1995). The assay was conducted in agar plates of assay medium ("Microorganisms") seeded with $C$. albicans MTCC 227 as test organism. From the mean diameter of the inhibition zones the concentration of rapamycin was empirically determined. Rapamycin concentration was determined using high performance liquid chromatography (HPLC). A calibration curve of different concentrations of rapamycin standard versus area of HPLC peak was plotted and unknown concentration of rapamycin in the supernatant was calculated using the linear equation obtained from the calibration curve. All experiments were done in triplicate. For sample preparation, the supernatant was filtered through $0.22-\mu \mathrm{m}$ membrane filters for organic solvents (Pall Corporation, India). After appropriate dilutions with HPLC-grade methanol, samples were analyzed by HPLC system (Waters ${ }^{\mathrm{TM}}$ 600) equipped with UV/visible detector and a $\mathrm{C}_{18}$ hypersil column $(4.6 \times 250 \mathrm{~mm} ; 5 \mu \mathrm{m}$ particle size; Waters, USA). Mobile phase used was methanol:acetonitrile $(80: 20 \mathrm{v} / \mathrm{v})$, at a flow rate of $1 \mathrm{~mL} / \mathrm{min}$. An aliquot of $20 \mu \mathrm{L}$ of filtrate supernatant was injected and analyzed at $272 \mathrm{~nm}$ using the UV/visible detector.

\section{Mathematical background}

In Monod's model, the growth rate is related to the concentration of a single growth-limiting substrate through the parameters $\mu_{\max }$ and $K_{\mathrm{S}}$. Monod model also relates the yield coefficient $\left(Y_{\mathrm{X} / \mathrm{S}}\right)$ to the $\mu$ (Okpokwasili and Nweke 2005). The specific growth rate in the exponential phase was calculated using the following equation:

$\frac{\mathrm{d} X}{\mathrm{~d} t}=\mu X$

GraphPad Prism 5 software was used to calculate the kinetics parameters from the Monod equation: 
$\mu=\frac{\mu_{\max } S}{K_{\mathrm{S}}+S}$

When higher substrate concentration inhibits cell growth, the original Monod model becomes unsatisfactory. In this case, Monod derivatives that provided corrections for substrate inhibition (by incorporating the inhibition coefficient $K_{\mathrm{i}}$ ) can be used to describe the kinetics study. Among the substrate inhibition models, the Andrew's equation is most widely used (Okpokwasili and Nweke 2005). After evaluating several kinetic models (Yano, Aiba) the Andrew's model was best fitted and gave the highest $R^{2}$ value.

$\mu=\frac{\mu_{\max } S}{S^{2} K_{\mathrm{i}}+S+K_{\mathrm{S}}}$

The substrate utilization kinetics is given by Eq. (4). A carbon substrate is used to form cell material and metabolic products as well as for maintenance of the cell.

$\frac{\mathrm{d} S}{\mathrm{~d} t}=-\frac{1}{Y_{\mathrm{X} / \mathrm{S}}} \frac{\mathrm{d} X}{\mathrm{~d} t}-\frac{1}{Y_{\mathrm{P} / \mathrm{S}}} \frac{\mathrm{d} P}{\mathrm{~d} t}-m X$

However, if the substrate used for product formation and cell maintenance is assumed to be negligible, Eq (4) can be written as:

$\frac{\mathrm{d} S}{\mathrm{~d} t}=-\frac{1}{Y_{\mathrm{X} / \mathrm{S}}} \frac{\mathrm{d} X}{\mathrm{~d} t}$

Now, $Y_{\mathrm{X} / \mathrm{S}}$ is the ratio of cell mass growth and substrate concentration used for cell growth. $Y_{\mathrm{X} / \mathrm{S}}$ can be expressed as:

$Y_{\mathrm{X} / \mathrm{S}}=-\frac{\mathrm{d} X}{\mathrm{~d} S}$

$Y_{\mathrm{X} / \mathrm{S}}$ was calculated from experimental data using the Eq. (7).

$Y_{\mathrm{X} / \mathrm{S}}=\frac{X-X_{0}}{S_{0}-S}$

\section{Results and discussion}

For rapamycin production, we evaluated four different combinations (1. glucose, 2. fructose, 3 . fructose + mannose and 4. mannose) of carbon sources for better production. It can be seen in Fig. 1, among the carbohydrates used fructose yielded highest rapamycin titer. Catabolite repression may be the most likely reason for this lagging effect (Priest 1977; Kumar et al. 1999). It was previously established that a catabolite control protein (CcpA) was responsible for this regulatory mechanisms which transduced signal for the repression in rapamycin. Synthesis (Tobisch et al. 1999). The result is as accordance with Kojima et al. (1995).Therefore, we selected fructose in further studies replacing all other carbon sources by the same amount as they have same molecular mass (180.16 g/ mol) as well as same empirical formula $\left(\mathrm{C}_{6} \mathrm{H}_{12} \mathrm{O}_{6}\right)$. Although carbohydrates are also present in other media constituents, viz. malt extract, it is hard to analyze the amount of sugar present in the constituents and the amount utilized. Hence, analysis of substrate utilization was done by assuming supplemented carbohydrates as sole source of carbon and energy, thereby neglecting the amount of carbohydrate present in other media constituents. This result contradicts the findings reported by Lee et al., where they showed that a combination of fructose and mannose resulted in good growth of the organisms and consequent higher rapamycin titer (Lee et al. 1997). However, our result suggested that fructose together with nitrogen source casein and $\left(\mathrm{NH}_{4}\right)_{2} \mathrm{SO}_{4}$ supported good growth and rapamycin production by the employed strain (Fig. 1).

To study the effect of $S$ on $\mu, \mu$ for different $S$ was calculated using Eq. (1) while $X$ was obtained at different intervals of the incubation period. The values of $\mu$ for different $S$ were fitted to Monod's model using GraphPad Prism 5 software. The growth kinetic parameters, viz. $\mu_{\max }$ and $K_{\mathrm{S}}$ were found to be $0.003869 \mathrm{~h}^{-1}$ and $0.8271 \mathrm{~g} / \mathrm{L}$. The lower correlation coefficient $\left(R^{2}\right)$ value of 0.8713 found in Monod's model suggested that there was reasonable substrate or product inhibition on growth of the organism (Bhunia et al. 2012). Analysis of the Monod's model under different substrate concentration conditions suggested that fructose concentration regulates the microbial growth pattern. Since, there was no report of product inhibition for rapamycin production, the effect of substrate inhibition was only considered for modeling. Several substrate inhibition kinetic models were examined and compared in this work (Table 1). Andrew's model for substrate inhibition on microbial growth was found to fit the experimental values well, since an $R^{2}$ value of 0.9849 was obtained (Fig. 2a). The values of $\mu_{\max }, K_{\mathrm{S}}$ and $K_{\mathrm{i}}$ were found to be $0.0083 \mathrm{~h}^{-1}, 2.835$ and $0.073 \mathrm{~g} / \mathrm{L}$, respectively. The higher $R^{2}$ value found with Andrew's model indicates that it is comparatively better fitted model for the experimental data than Monod and other substrate inhibition models (Table 1). In rapamycin production, the increase in biomass concentration was accompanied by a decrease of fructose concentration. It is assumed that fructose is consumed for cell growth and cell maintenance. $Y_{\mathrm{X} / \mathrm{S}}$ value was determined by averaging $Y_{\mathrm{X} / \mathrm{S}}$ values calculated using Eq. (7) at different data points (Fig. 2b). Its values ranged from 0.0598 to 0.1708 and were found to be maximal at lower $S$ and minimal at higher $S$ because of the substrate inhibition on $Y_{\mathrm{X} / \mathrm{s}}$. The average $Y_{\mathrm{X} / \mathrm{S}}$ value was calculated to be $0.107 \mathrm{~g} \mathrm{~g}^{-1}$ and was fairly constant up to fructose concentration of $0.548 \mathrm{~g} / \mathrm{L}$ and then decreased to minimal at fructose concentration of $27 \mathrm{~g} / \mathrm{L}$. 

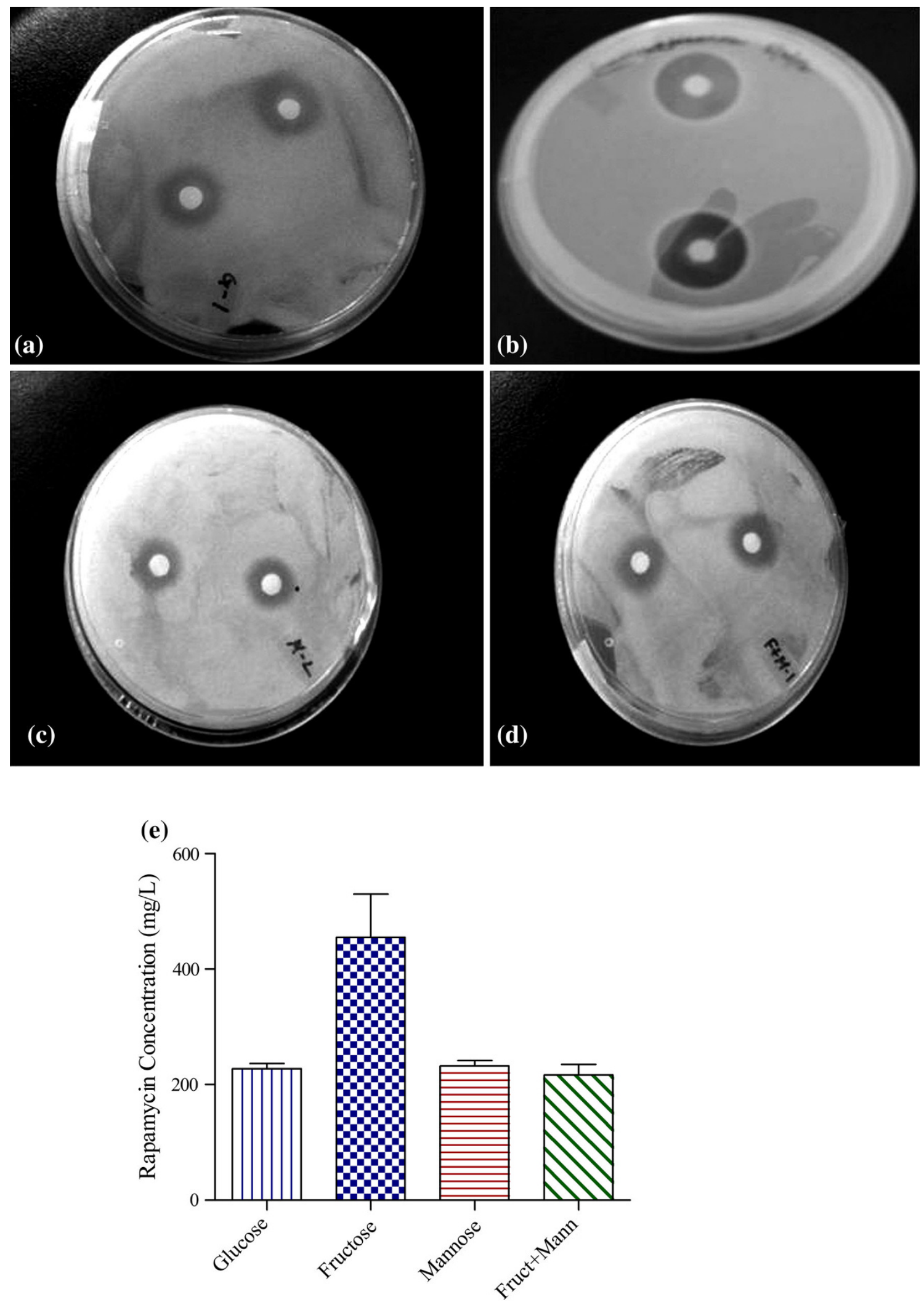

Substrates $(27 \mathrm{~g} / \mathrm{L})$

Fig. 1 Inhibition zones of rapamycin on agar plates of Candida albicans obtained using different carbon sources: a glucose, b fructose, c mannose, $\mathbf{d}$ fructose + mannose. e Concentrations of rapamycin found in shake flask using above-mentioned carbon sources 
Table 1 Growth kinetic parameters for $S$. hygroscopicus MTCC 4003 obtained by different models

\begin{tabular}{lllll}
\hline Mathematical models & $\begin{array}{l}\mu_{\max } \\
\left(\mathrm{h}^{-1}\right)\end{array}$ & $\begin{array}{l}K_{\mathrm{S}} \\
(\mathrm{g} / \mathrm{L})\end{array}$ & $\begin{array}{l}K_{\mathrm{i}} \\
(\mathrm{g} / \mathrm{L})\end{array}$ & $R^{2}$ \\
\hline $\begin{array}{l}\text { Andrew's model } \\
\quad \begin{array}{l}\mu_{\max } S \\
S^{2} K_{\mathrm{i}}+S+K_{\mathrm{S}}\end{array}\end{array}$ & 0.0083 & 2.835 & 0.073 & 0.9849 \\
$\begin{array}{l}\text { Yano model } \\
\mu=\frac{\mu_{\max } S}{S+K_{\mathrm{S}}+\left(\frac{S^{2}}{K_{\mathrm{i}}}+\frac{S^{3}}{K_{\mathrm{i}}^{2}}\right)}\end{array}$ & 0.0071 & 2.324 & 29.21 & 0.9818 \\
& & & & \\
$\begin{array}{l}\text { Aiba model } \mu=\frac{\mu_{\max } S}{K_{\mathrm{S}}+S} e^{\left(-S+K_{\mathrm{i}}\right)} \\
\text { Monod model } \mu=\frac{\mu_{\max } S}{K_{\mathrm{S}}+S}\end{array}$ & 0.0078 & 2.540 & 0.03963 & 0.9813 \\
& 0.003869 & 0.8271 & - & 0.8713 \\
\end{tabular}

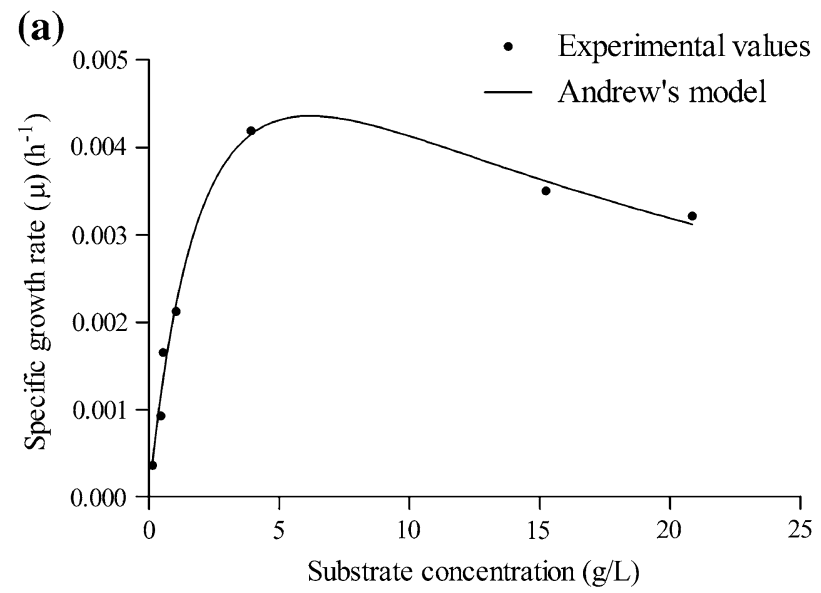

(b)

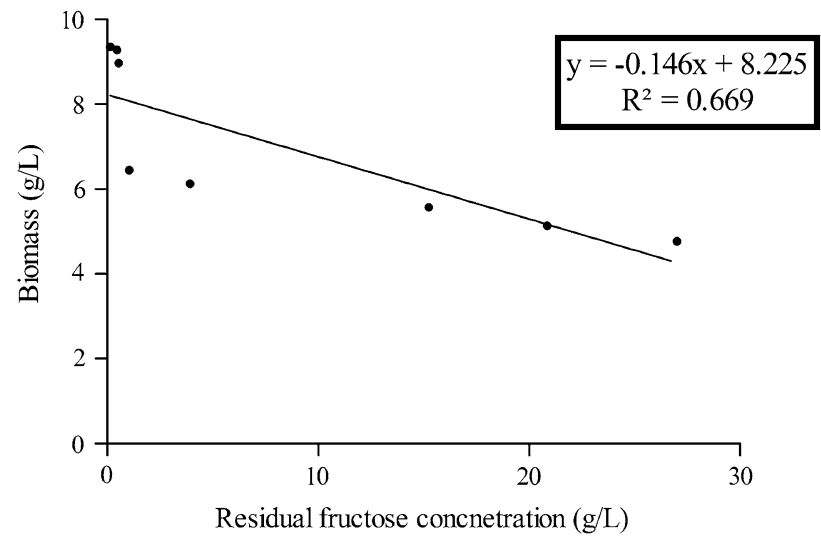

Fig. 2 a Relationship between specific growth rate $(\mu)$ and substrate concentrations $(S)$. b Determination of growth yield coefficient $\left(Y_{\mathrm{X} / \mathrm{S}}\right)$

The fermentor was operated with constant impeller speed of $300 \mathrm{rpm}$ for 8 consecutive days. The dissolved oxygen (DO) plays a vital role in the rapamycin production. The air flow rate was kept constant at $1 \mathrm{vvm}$ throughout the fermentation process. Initially DO was set at $100 \%$ at the time of inoculation, while during the lag phase microorganisms did not start to utilize the carbon of the media. However, when the fermentation enters the log phase, dissolved oxygen rapidly decreases as a result of increase in oxygen demand by the cells. Therefore, the dissolved oxygen level decreases and finally reached a certain stationary value. Finally, the DO level was maintained at $10 \%$ of saturation level all the time (Zhu et al. 2010).

An antibiotic is a secondary metabolite which is synthesized mainly at the stationary phase of growth of a microorganism. However, the obtained data clearly show that exponential phase of growth is very important for rapamycin production (Zhu et al. 2010; Sanchez and Brana 1996). Streptomyces hygroscopicus MTCC 4003 showed a conventional growth pattern during the batch fermentation in the bioreactor (Fig. 3a). The production of rapamycin was started after $24 \mathrm{~h}$ of incubation and reached a maximal at $144 \mathrm{~h}$ (Fig. 3a). Similar trends were also reported in the literature (Xu et al. 2005; Lee et al. 1997). Rapamycin production was observed to increase rapidly during end of the exponential phase and early stationary phase (Xu et al. 2005). The productivity $(\mathrm{mg} / \mathrm{L} \mathrm{h})$ is defined as the amount of product formation per unit of time. In the present study, we compared rapamycin productivity $(\mathrm{d} P / \mathrm{d} t)$ in shake flask with that of bioreactor. Figure $3 \mathrm{~b}$ represents the difference of rapamycin productivity in shake flask and bioreactor. Comparison of rapamycin production by different strains under various fermentation processes has been described in Table 2. Zhu et al., reported maximum productivity of rapamycin in fed-batch operate mode of 20,000 -L fermentor, which is maximum productivity in fermentor reported till date (Zhu et al. 2010). In the present study, maximum rapamycin productivity of $9.13 \mathrm{mg} / \mathrm{L} \mathrm{h}^{-1}$ was obtained in bioreactor (Table 2).

The production of rapamycin was detected using HPLC analysis. The calibration curve of rapamycin standard was prepared by plotting HPLC peak area against known rapamycin standard concentrations $\left(R^{2}=0.9954\right)$ (Fig. 4a). For each concentration of rapamycin standard HPLC retention time (RT) was found to be $2.884 \mathrm{~min}$ (Fig. 4b). The methanolic extract of the supernatant was analyzed for presence of rapamycin. Its presence was confirmed by its retention time (2.814 $\mathrm{min})$ which is about same as that of rapamycin standard (Fig. 4c). Figure 3c represents the HPLC chromatogram of methanolic extract of supernatant after 6 days of fermentation. Concentrations of rapamycin in the production medium were obtained by measuring HPLC peak areas (Refaat and Abdel-Fatah 2008). From the equation given in the Fig. 3a, the concentration of the 6th day's sample was calculated to be $1,316.02 \mathrm{mg} / \mathrm{L}$ which is the highest rapamycin produced in the bioreactor till date. It is $52 \%$ higher than that reported previously $(860.6 \mathrm{mg} / \mathrm{L})$ by Zou and $\mathrm{Li}$ (2013). On the 12th day of fermentation, rapamycin 
Fig. 3 Time-course profile of cell growth, rapamycin production, and substrate utilization

\section{(a)}

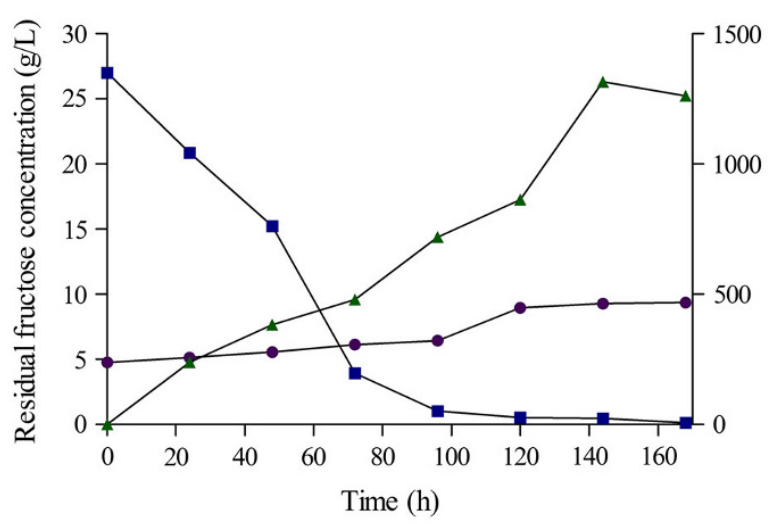

Biomass $(\mathrm{g} / \mathrm{L})$

$\rightarrow$ Residual fructose concentration $(\mathrm{g} / \mathrm{L})$

$\approx \rightarrow$ Rapamycin concentration (b)

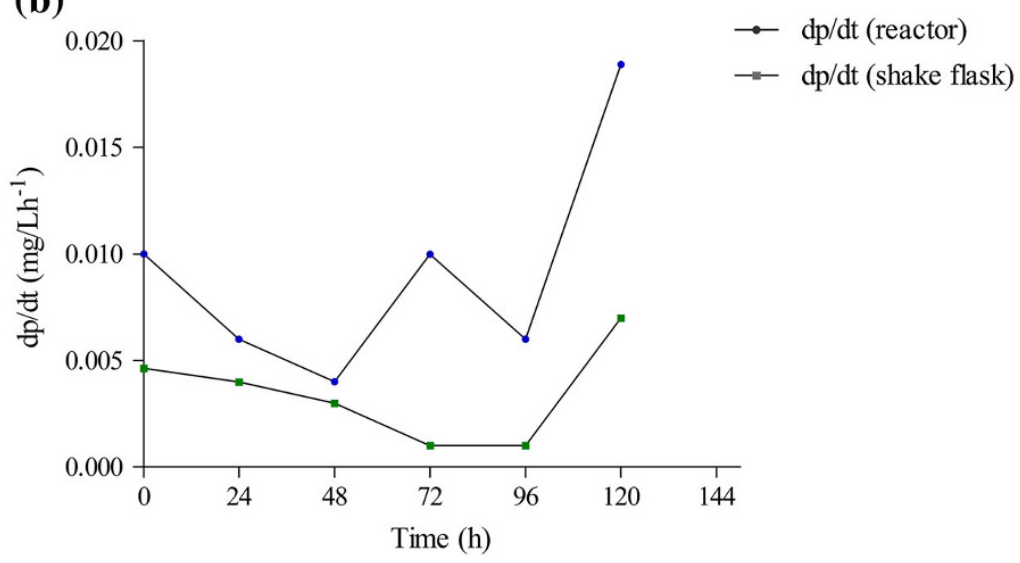

Table 2 Comparison of rapamycin production by different strains under various fermentation processes

\begin{tabular}{|c|c|c|c|c|c|c|}
\hline Microorganism & Bioreactor & Operate mode & Time (h) & $\begin{array}{l}\text { Rapamycin } \\
\text { titer }(\mathrm{mg} / \mathrm{L})\end{array}$ & $\begin{array}{l}\text { Productivity } \\
\text { (mg/L h) }\end{array}$ & References \\
\hline S. hygroscopicus $\mathrm{C} 9$ & Shake flask & Batch & 144 & 186 & 1.29 & Fang and Demain (1995) \\
\hline S. hygroscopicus $\mathrm{C} 9$ & Shake flask & Batch & 144 & 130 & 0.90 & Lee et al. (1997) \\
\hline S. hygroscopicus NBS-9746 & 130L fermentor & Fed Batch & 110 & 110 & 1.0 & Cheng (1995) \\
\hline S. hygroscopicus N5632 & Shake flask & Batch & 120 & 420 & 3.5 & Xu et al. (2005) \\
\hline S. hygroscopicus GS-1437 & Shake flask & Batch & 120 & 445 & 3.71 & Chen et al. (2009) \\
\hline S. hygroscopicus R060107 & $5 \mathrm{~L}$ fermentor & Fed batch & 120 & 500 & 4.17 & Chen et al. (2008) \\
\hline S. hygroscopicus HD-04-S & $20,000 \mathrm{~L}$ fermentor & Fed batch & 168 & 783 & 4.66 & Zhu et al. (2010) \\
\hline S. hygroscopicus ATCC 29253 & Tubes & Batch & 120 & 42.8 & 0.36 & Jung et al. (2011) \\
\hline S. hygroscopicus FMT11 & 7L fermentor & Fed batch & 204 & 860.6 & 4.22 & Zou and Li (2013) \\
\hline S. hygroscopicus МТCC4003 & Shake flask & Batch & 144 & 539 & 3.74 & This study \\
\hline S. hygroscopicus MTCC 4003 & $2.2 \mathrm{~L}$ fermentor & Batch & 144 & $1,316.02$ & 9.13 & This study \\
\hline
\end{tabular}

concentration decreased significantly to $91.67 \mathrm{mg} / \mathrm{L}$. This phenomenon was observed by Xu et al. (2005) and might be attributed to the fact that rapamycin starts degrading after 7 days of fermentation (Prapagdee et al. 2008). This is also evident from Fig. $4 \mathrm{~d}$ that shows the lower rapamycin concentration noted in the 12th day's sample and formation of two adjacent peaks in the HPLC chromatogram might be attributed to degradation of rapamycin and consequent production of rapamycin degradation products (Prapagdee et al. 2008; Wang et al. 1994). 

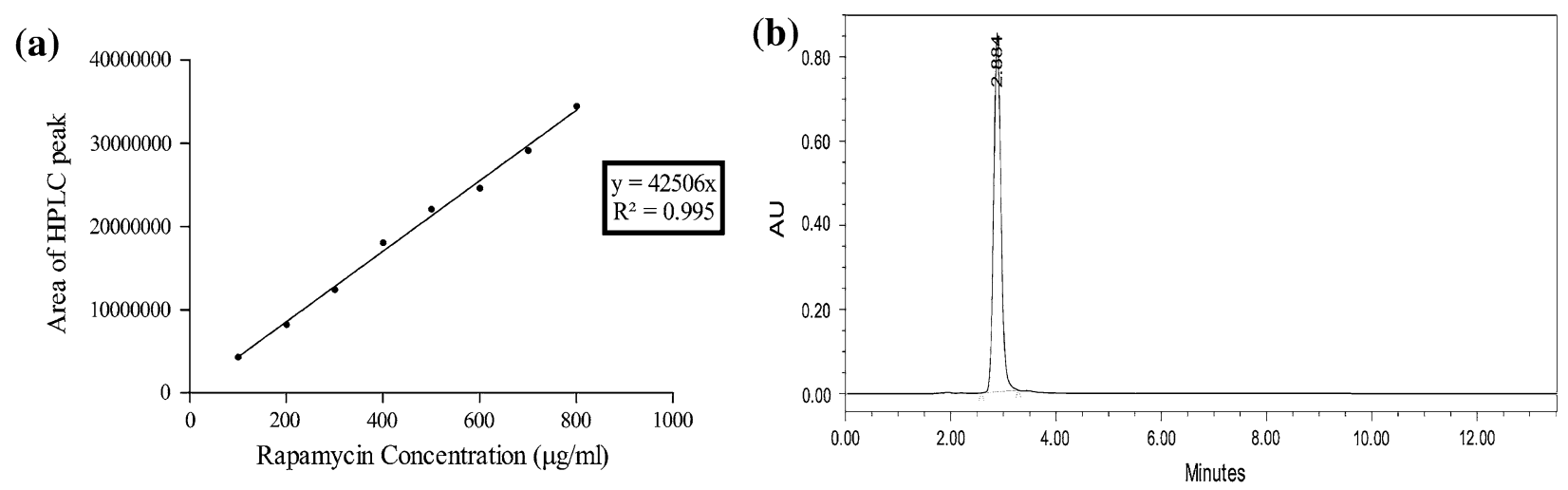

(c)
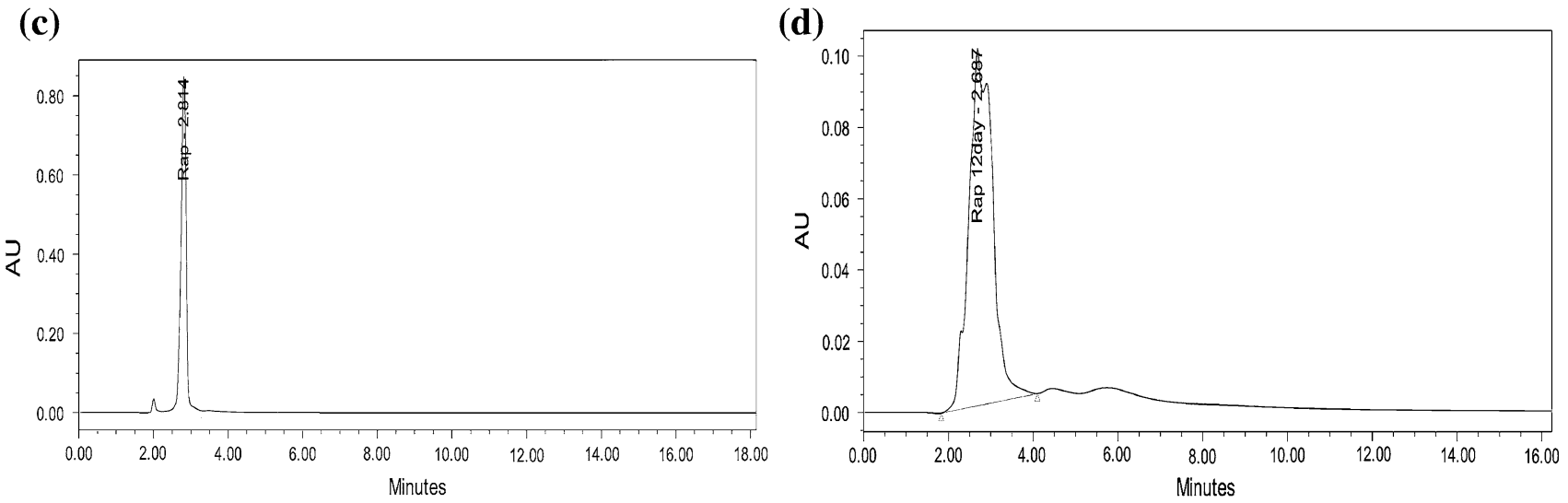

Fig. 4 a Calibration curve between the HPLC peaks areas and respective concentration of rapamycin standard; b HPLC peak of rapamycin standard; $\mathbf{c}$ HPLC analysis of rapamycin produced on 6th day of fermentation; d HPLC analysis of rapamycin on 12th day of fermentation

\section{Conclusion}

Fructose was found to be a better carbon source than mannose. The maximum production of rapamycin in the shake flask was found to be $539 \mathrm{mg} / \mathrm{L}$ using fructose as sole carbon source in combination with casein and $\left(\mathrm{NH}_{4}\right)_{2} \mathrm{SO}_{4}$. Extraction of rapamycin with methanol gave higher yield of rapamycin. Sixth day sample of fermentation gave the highest rapamycin titer of $1,316 \mathrm{mg} / \mathrm{L}$ in bioreactor quantified using HPLC technique.

Low titers of rapamycin produced by different strains of $S$. hygroscopicus limits the large-scale industrial production of this potent natural product. Therefore, different attempts, viz. strain improvement, process parameters optimization; precursor engineering studies have been employed to improve the production of this antibiotic. However, proper knowledge of nutritional requirements and kinetic behavior of the organism also need to be thoroughly studied if the maximum production of this immunosuppressant drug is intended. Therefore, the cell growth dynamic results obtained in the present study will help in the enhanced production of this drug.
Acknowledgments The authors would like to acknowledge Ministry of Human Research and Development, Govt. of India, for providing fund for this research.

Conflict of interest The authors would like to state that they have no potential conflict of interest regarding submission and publication of this manuscript.

Open Access This article is distributed under the terms of the Creative Commons Attribution License which permits any use, distribution, and reproduction in any medium, provided the original author(s) and the source are credited.

\section{References}

Bhunia B, Basak B, Bhattacharya P, Dey A (2012) Kinetic studies of alkaline protease from Bacillus licheniformis NCIM-2042. J Microbiol Biotechnol 22:1758-1766

Chen Y, Krol J, Huang W, Cino JP, Vyas R, Mirro R, Vaillancourt B (2008) DCO2 on-line 5 measurement used in rapamycin fedbatch fermentation process. Process Biochem 43:351-355

Chen X, Wei P, Fan L, Yang D, Zhu X, Shen W, Xu Z, Cen P (2009) Generation of high-yield rapamycin-producing strains through protoplasts-related techniques. Appl Microbiol Biotechnol 83(3):507-512. doi:10.1007/s00253-009-1918-7

Cheng YR (1995) Phosphate, ammonium, magnesium and iron nutrition of Streptomyces hygroscopicus with respect to rapamycin biosynthesis. J Ind Microbiol Biotechnol 14:424-427 
Fang A, Demain A (1995) Exogenous shikimic acid stimulates rapamycin biosynthesis in Streptomyces hygroscopicus. Folia Microbiol 40:607-610

Foroncewicz B, Mucha K, Paczek L, Chmura A, Rowinski W (2005) Efficacy of rapamycin in patient with juvenile rheumatoid arthritis. Transpl Int 18(3):366-368. doi:10.1111/j1432-2277 200400070x

Graziani EI (2009) Recent advances in the chemistry, biosynthesis and pharmacology of rapamycin analogs. Nat Prod Rep 26(5):602-609. doi:10.1039/b804602f

Jung WS, Yoo YJ, Park JW, Park SR, Han AR, Ban YH, Kim EJ, Kim E, Yoon YJ (2011) A combined approach of classical mutagenesis and rational metabolic engineering improves rapamycin biosynthesis and provides insights into methylmalonyl-CoA precursor supply pathway in Streptomyces hygroscopicus ATCC 29253. Appl Microbiol Biotechnol 91(5):1389-1397. doi:10. 1007/s00253-011-3348-6

Kojima I, Cheng YR, Mohan V, Demain AL (1995) Carbon source nutrition of rapamycin biosynthesis in Streptomyces hygroscopicus. J Ind Microbiol 14(6):436-439

Kumar CG, Malik RK, Tiwari MP, Jany KD (1999) Optimal production of Bacillus alkaline protease using a cheese whey medium. Microbiologie des Alimentes et Nutr 17:39-48

Lee MS, Kojima I, Demain AL (1997) Effect of nitrogen source on biosynthesis of rapamycin by Streptomyces hygroscopicus. J Ind Microbiol Biotechnol 19:83-86

Miller GL (1959) Use of dinitrosalicylic acid reagent for determination of reducing sugar. Anal Chem 31(3):426-428

Morelon E, Mamzer-Bruneel MF, Peraldi MN, Kreis H (2001) Sirolimus: a new promising immunosuppressive drug. Towards a rationale for its use in renal transplantation. Nephrol Dial Transplant 16:18-20

Nicoletti F, Lapenta C, Donati S, Spada M, Ranazzi A, Cacopardo B, Mangano K, Belardelli F, Perno C, Aquaro S (2009) Inhibition of human immunodeficiency virus (HIV-1) infection in human peripheral blood leucocytes-SCID reconstituted mice by rapamycin. Clin Exp Immunol 155(1):28-34. doi:10.1111/j13652249200803780xCEI3780

Okpokwasili GC, Nweke CO (2005) Microbial growth and substrate utilization kinetics. Afr J Biotechnol 5:305-317

Park SR, Yoo YJ, Ban YH, Yoon YJ (2010) Biosynthesis of rapamycin and its regulation: past achievements and recent progress. J Antibiot (Tokyo) 63(8):434-441. doi:10.1038/ ja201071ja201071

Prakasham RS, Subba Rao C, Sreenivas Rao R, Sarma PN (2007) Enhancement of acid amylase production by an isolated Aspergillus awamori. J Appl Microbiol 102(1):204-211. doi:10.1111/j1365-2672200603058x

Prapagdee B, Kuekulvong C, Mongkolsuk S (2008) Antifungal potential of extracellular metabolites produced by Streptomyces hygroscopicus against phytopathogenic fungi. Int $\mathrm{J}$ Biol Sci 4:330-337

Priest FG (1977) Extracellular enzyme synthesis in the genus Bacillus. Bacteriol Rev 41(3):711-753

Refaat Y, Abdel-Fatah E (2008) Non conventional method for evaluation and optimization of medium components for rapamycin production by Streptomyces hygroscopicus. Res J Microbiol 3:405-413

Sabatini DM, Pierchala BA, Barrow RK, Schell MJ, Snyder SH (1995) The rapamycin and FKBP12 target (RAFT) displays phosphatidylinositol 4-kinase activity. J Biol Chem 270: 20875-20878

Sallam L, El-Refai A, Osman M (2010) Some physiological factors affecting rapamycin production by Streptomyces hygroscopicus ATCC 29253. J Am Sci 6(6):188-194

Sanchez L, Brana AF (1996) Cell density influences antibiotic biosynthesis in Streptomyces clavuligerus. Microbiol 142(Pt 5): 1209-1220

Schuhmann E, Bergter F (1976) Microscopic studies of Streptomyces hygroscopicus growth kinetics. Z Allg Mikrobiol 16(3):201-205

Sehgal SN (2003) Sirolimus: its discovery, biological properties, and mechanism of action. Transplant Proc 35(3 Suppl):7S-14S (pii:S0041134503002112)

Subba Rao C, Madhavendra SS, Sreenivas Rao R, Hobbs PJ, Prakasham RS (2008) Studies on improving the immobilized bead reusability and alkaline protease production by isolated immobilized Bacillus circulans (MTCC 6811) using overall evaluation criteria. Appl Biochem Biotechnol 150(1):65-83. doi:10.1007/s12010-008-8147-x

Tain LS, Mortiboys H, Tao RN, Ziviani E, Bandmann O, Whitworth AJ (2009) Rapamycin activation of 4E-BP prevents parkinsonian dopaminergic neuron loss. Nat Neurosci 12(9):1129-1135. doi:10.1038/nn2372nn2372

Tobisch S, Zuhlke D, Bernhardt J, Stulke J, Hecker M (1999) Role of $\mathrm{CcpA}$ in regulation of the central pathways of carbon catabolism in Bacillus subtilis. J Bacteriol 181(22):6996-7004

Wang CP, Chan KW, Schiksnis RA, Scatina J, Sisenwine SF (1994) High performance liquid chromatographic isolation, spectroscopic characterization, and immunosuppressive activities of two rapamycin degradation products. J Liq Chromatogr Relat Technol 17:3383-3392

Weber T, Abendroth D, Schelzig H (2005) Rapamycin rescue therapy in patients after kidney transplantation: first clinical experience. Transpl Int 18(2):151-156. doi:10.1111/j1432-2277200400032x

Wiederrecht GJ, Sabers CJ, Brunn GJ, Martin MM, Dumont FJ, Abraham RT (1995) Mechanism of action of rapamycin: new insights into the regulation of G1-phase progression in eukaryotic cells. Prog Cell Cycle Res 1:53-71

Xu Z-N, Shen W-H, Chen X-Y, Lin J-P, Cen P-L (2005) A high throughput method for screening of rapamycin-producing strains of Streptomyces hygroscopicus by cultivation in 96-well microtiter plate. Biotechnol Lett 27:1135-1140

Zhu X, Zhang W, Chen X, Wu H (2010) Generation of high rapamycin producing strain via rational metabolic pathwaybased mutagenesis and further titer improvement with fed -batch bioprocess optimization. Biotechnol Bioeng 107:506-514. doi:10.1002/bit.22819

Zou X, Li J (2013) Precursor engineering and cell physiological regulation for high level rapamycin production by Streptomyces hygroscopicus. Ann Microbiol. doi:10.1007/s13213-1301210597-13212101007 